\title{
APPLICATION OF PROTON MAGNETIC RESONANCE FOR DETECTION OF FRACTURED CHALK AQUIFERS FROM THE SURFACE
}

\author{
A.V. Legchenko, J.M. Baltassat, A. Beauce, BRGM, France and D. Chigot, Antea, France
}

\begin{abstract}
Direct measurement of Proton Magnetic Resonance (PMR) signal from water molecules guarantees a high reliability of the water detection. It is the main distinction of the PMR compared to other geophysical tools. Interpretation of experimental data reveals location of aquifers, theirs depth and water content. A mean size of pores of the water-saturated rocks can also be estimated.

Currently the method is mostly developed for investigation of sedimentary aquifers. Meanwhile the physical principles of the method allow to use it also for detection of water in fractured rocks and for discrimination among aquifers composed by different types of rock. This field study was performed in order to calibrate the PMR signal generated by water in fractured chalk aquifers.

It was found that the decay time of the PMR signal is the most suitable parameter which can be used for characterization of aquifers. However, the water content is also an important parameter for localization of aquifers and for comparison of bulk volume of water in aquifers composed by similar rocks.
\end{abstract}

\section{INTRODUCTION}

The Surface PMR method for water prospecting was recently developed in Russia and this method is now a subject for further development in BRGM. The main preference of the PMR in comparison with other geophysical methods is a direct correlation of the PMR signal with existence or absence of water.

In order to detect fractured waterfull zones, which can be used for water supply of Saint Brisson sur Loire (France), a field study was performed by BRGM in November-December of 1996. Totally 17 sites around St. Brisson were investigated by PMR. Results of this PMR survey were compared with boreholes data.

\section{METHOD}

A wire loop is laid down on the ground. It is energized by a pulse of alternating current

$$
i(t)=I_{0} \cos \left(\omega_{0} t\right) \text {. }
$$


Frequency of the current is equal to the Larmor frequency in the geomagnetic field $H_{0}$

$$
\omega_{0}=\gamma H_{0},
$$

where $\lambda$ is the gyromagnetic ratio for protons. The method is selective and no other response at this frequency can appear. The PMR signal is

$$
e(t)=E_{0}(q) \sin \left(\omega_{0} t+\varphi_{0}\right) \exp \left(-t / T_{2}^{*}\right),
$$

where $T_{2}^{*}$ is the spin-spin relaxation time and $\varphi_{0}$ is the phase. The amplitude $E_{0}(q)$ and the decay time $T_{2}^{*}(q)$ are measured varying the pulse parameter $q=I_{0} \tau$, where $I_{0}, \tau$ are the amplitude and duration of the pulse respectively. Joint inversion of the $E_{0}(q)$ and $T_{2}^{*}(q)$ data allows determination of the vertical distributions of water content and decay time.

Using the water content, the bulk volume of water, the depth and the thickness of aquifers can be found. For example, the water content in waterless rocks is equal to zero, and in a bulk water of a lake it is equal to $100 \%$. The decay time correlates with a mean size of pores of water-containing rocks. Empirical relationship between the decay time and the type of rocks is shown in the table (Shirov et al.,1991):

\begin{tabular}{|c|c|}
\hline Decay time (ms) & Water containing strata \\
\hline$<30$ & sandy clays \\
$30-60$ & clayey sands, very fine sands \\
$60-120$ & fine sands \\
$120-180$ & medium sands \\
$180-300$ & coarse and gravelly sands \\
$300-600$ & gravel deposits \\
$600-1000$ & surface water bodies \\
\hline
\end{tabular}

\section{RESULTS}

Field measurements were performed by the NUMIS PMR instrument. During this survey an antenna in a shape of figure eight was used. The maximum depth of investigation with this antenna is approximately $40-50$ meters.

Geology of St. Brisson area is presented by chalk overlaid by rather irregular 5-20 meter thick layers of clay and sand. If the upper part of the chalk is fractured, it might contain water. These fractured zones are used for water supply. Sand and clay aquifers also can be saturated by water, but yield of these aquifers is relatively small and unstable (Chigot, 1996).

In order to demonstrate capability of the PMR to discriminate aquifers composed by different rocks we present here results obtained over three sites. The PMR data were compared with borehole data. Site 1 presents a fractured chalk aquifer fulfilled by mud. Yield of the borehole on this site was found to be less than $1 \mathrm{~m}^{3} / h$. This type of aquifer can not be used for water 
supply. The borehole drilled on site 2 produces $18 \mathrm{~m}^{3} / \mathrm{h}$. On this site the aquifer is composed essentially by fractured chalk. This type of rock can be used for water supply and it is a target for water investigation. Sand and clay aquifer on site 3 is rather irregular and is not a matter of our interest. Results of field measurements (the amplitude and the decay time) are depicted in Figure 1. The signal (and hence the water) was detected in all three sites. The largest amplitude was found on site 1 which corresponds to the largest volume of water. But the smallest decay time indicates that most of the water in this aquifer is bounded and we should expect rather low yield for a borehole (and this was proved later after drilling). Sand and clay aquifer on site 3 produces the longest signal (the largest decay time) and from the PMR data we may expect better yield than on site 1. But sand lenses are hydraulically separated in this area and after a short period of time the borehole produces almost nothing. The decay time on site 2 was found to be about $80 \mathrm{~ms}$. Measurements over fractured chalk aquifers at few other sites also indicated a decay time of about $80-100 \mathrm{~ms}$. With some degree of reliability this decay time value can be used as a specific characteristic of the waterfull fractured chalk.

Inversion results are shown in Figure 2. They generally correspond well to aquifers detected by boreholes. Reconstructed theoretical signals shown in Figure 1 by solid lines fit well experimental data.

\section{CONCLUSIONS}

Field measurements in St-Brisson area demonstrated that in complicated hydrogeological environment (different types of water-saturated rocks), reliable detection of presence or absence of subsurface water is not sufficient for resolving water supply problems.

In order to calibrate the PMR response different aquifers in St-Brisson area were investigated. It was experimentally found that a decay time of 80-100 ms may characterize fractured chalk aquifers useful for water supply purposes. Aquifers which generate signals with decay times lower than $60 \mathrm{~ms}$ can also be composed by fractured chalk, but they do not produce much water. Decay times greater than $150 \mathrm{~ms}$ correspond to water-saturated sand aquifers. The water content is a less reliable characteristic of the aquifers. It can be explained by the fact that bounded water also gives a PMR response but this water can be hardly extracted from the aquifer.

In general, a decay time of $80-100 \mathrm{~ms}$ can be also found over sedimentary aquifers. Hence it cannot be used as the unique parameter for discrimination of fractured zones everywhere without signal-calibration.

\section{REFERENCES}

Chigot, D., 1996, Compte rendu da la campagne de sondage de reconnaisance réalisée sur la commune de Saint Brisson sur Loire (45), rapport ANTEA, Novembre 1996. (in French)

Shirov, M., Legchenko, A., and Creer, G., 1991, New direct non-invasive ground water detection technology for Australia: Expl. Geophys., 22, 333-338. 

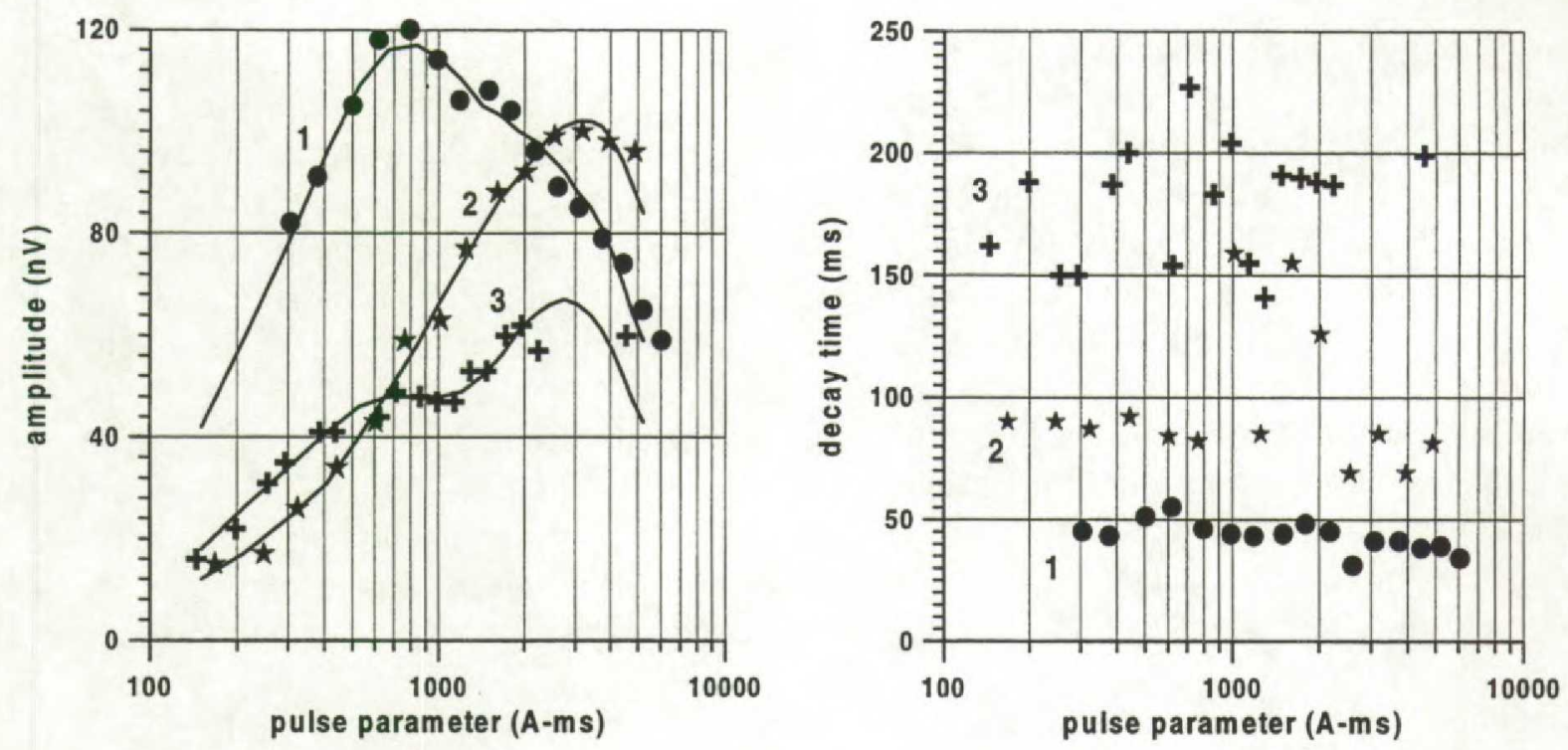

FIG.1. Measured parameters of the PMR signal. 1 - fractured chalk fulfilled with mud; 2 fractured chalk; 3 - sand and clay. Solid line - theoretical signal calculated using results of inversion.
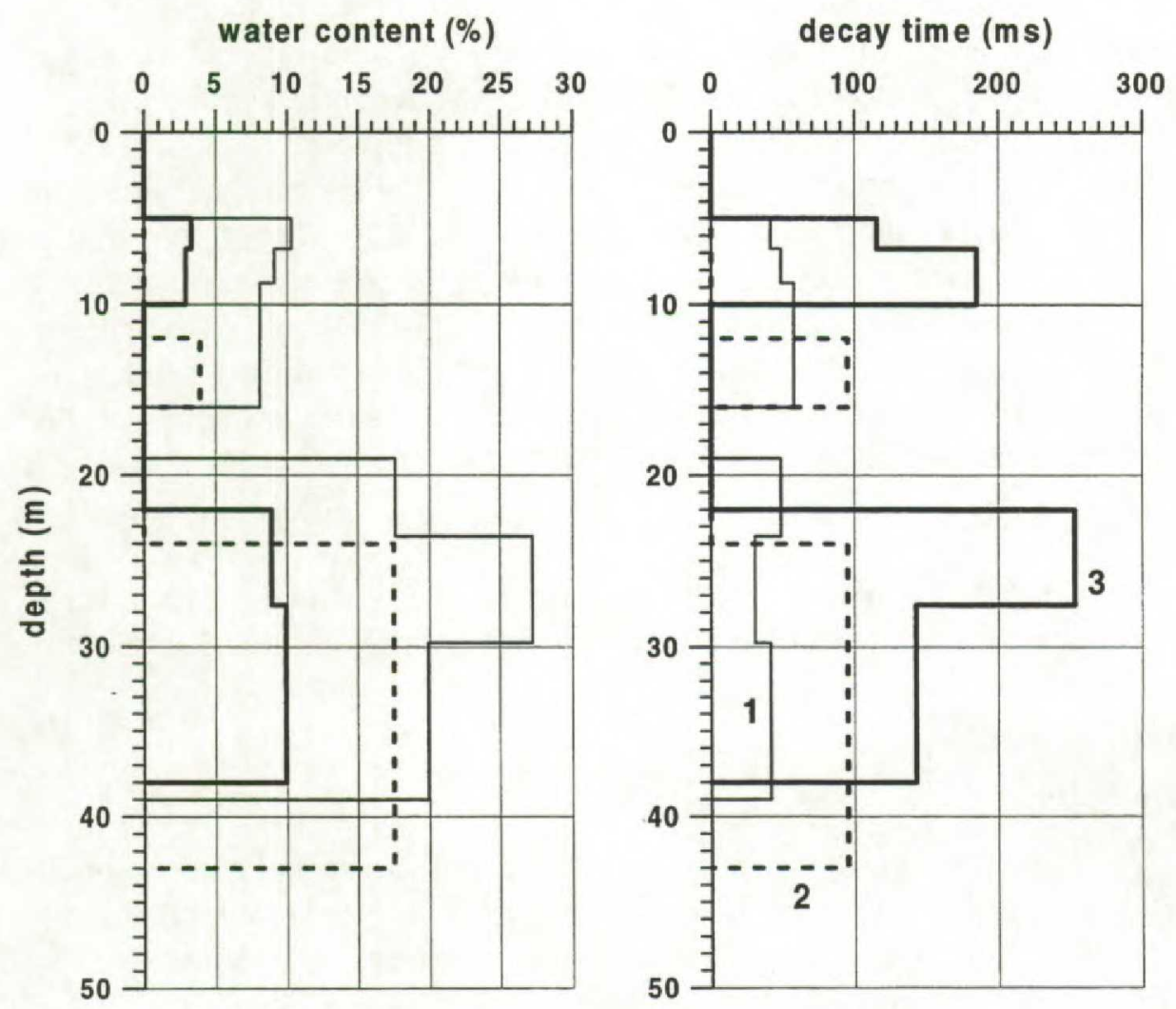

FIG.2. Inversion results. 1 - fractured chalk fulfilled with mud; 2 - fractured chalk; 3 - sand and clay. 